Cite this: RSC Adv., 2014, 4, 11580

Received 18th December 2013 Accepted 14th February 2014

DOI: $10.1039 / c 3 r a 47730 d$

www.rsc.org/advances

\section{Mesoporous manganese-deficient lithium manganese silicate cathodes for lithium-ion batteries $\uparrow$}

\author{
Rosalind J. Gummow ${ }^{\star a}$ and Yinghe $\mathrm{He}^{\mathrm{b}}$
}

\begin{abstract}
Mesoporous electrode materials are favourable for lithium-ion batteries as they have high surface area and provide short lithium-ion diffusion distances from the pore space into the thin pore walls. The porous morphology is also an advantage for buffering the large volume changes that can accompany lithium insertion and extraction. For this reason, this study investigates the synthesis of mesoporous lithium manganese silicate, using mesoporous silica as a template. It is shown that a mesoporous lithium manganese silicate product, retaining the mesoporous symmetry of the SBA-15 silica precursor, can be formed by emulsion synthesis followed by calcination in an inert atmosphere at $700{ }^{\circ} \mathrm{C}$. These calcination conditions retain the decomposed surfactant as a conductive surface layer on the product phase. Undesired, electrochemically inactive $\mathrm{MnO}$ impurities were minimized by reducing the $\mathrm{Li}: \mathrm{Mn}$ ratio to $2: 0.7$ in the starting mixture. Rietveld analysis of the X-ray diffraction patterns of the product shows that it is manganese deficient with composition $\mathrm{Li}_{2} \mathrm{Mn}_{0.87(3)} \mathrm{SiO}_{4}$ with minor impurities of $\mathrm{MnO}$ and $\mathrm{Li}_{2} \mathrm{SiO}_{3}$. Excellent reversibility is observed for these cathodes in lithium cells with a capacity of $175 \mathrm{~mA} \mathrm{~h} \mathrm{~g}^{-1}$ when cycled in constant current-constant voltage mode at a current rate of $20 \mathrm{~mA} \mathrm{~g}^{-1}$.
\end{abstract}

Rechargeable lithium-ion batteries are commonly used today to power portable, electronic devices. Lithium-ion batteries are also being applied as batteries for electric vehicles and for largescale storage of energy generated from intermittent renewable sources like solar and wind power. Consumer demands for high capacity, long calendar life and low cost are driving the development of new electrode materials to advance this technology. ${ }^{1-4}$

${ }^{a}$ School of Engineering and Physical Sciences, James Cook University, Townsville, Queensland, Australia. E-mail: Rosalind.gummow@jcu.edu.au; Fax: +61 747816788; Tel: +61747816223

${ }^{b}$ School of Engineering and Physical Sciences, James Cook University, Townsville, Queensland, Australia. E-mail: Yinghe.he@jcu.edu.au; Fax: +61 747816788; Tel: +61747814312

$\dagger$ Electronic supplementary information (ESI) available. See DOI: $10.1039 / \mathrm{c} 3 \mathrm{ra} 47730 \mathrm{~d}$
Mesoporous materials are ordered, porous materials with pores in the range $2-50 \mathrm{~nm}$, typically formed using either soft templates, for example surfactants, or hard templates like mesoporous silica or mesoporous carbon., ${ }^{5,6}$ Mesoporous materials have been used as lithium-ion battery electrodes for several reasons. ${ }^{7,8}$ Firstly, the interconnected network of pores allows electrolyte penetration into the bulk of the electrode enabling fast kinetics of lithium diffusion. Secondly, the short lithium diffusion distance from the pore space into the thin pore walls allows rapid kinetics and full utilization of the bulk of the material. Thirdly, the porosity allows accommodation of volumetric changes with cycling and results in stabilization of phases that do not cycle reversibly in bulk form.,

Lithium manganese silicate $\left(\mathrm{Li}_{2} \mathrm{MnSiO}_{4}\right)$ is an attractive option as a lithium ion battery cathode with a potential capacity above $300 \mathrm{~mA} \mathrm{~h} \mathrm{~g}^{-1}$ if both lithium ions can be extracted reversibly. ${ }^{11}$ The application of $\mathrm{Li}_{2} \mathrm{MnSiO}_{4}$ as a cathode material is, however, complex. The two main drawbacks of $\mathrm{Li}_{2} \mathrm{MnSiO}_{4}$ cathodes are, firstly, very low electronic conductivity ${ }^{12,13}$ resulting in large polarization and low capacity in bulk material, ${ }^{\mathbf{1 4}}$ and, secondly, structural collapse and amorphization as a result of the large volume changes that occur when large amounts of lithium are extracted on charge. ${ }^{12,13,15,16}$ The rapid loss of capacity with electrochemical cycling of $\mathrm{Li}_{2} \mathrm{MnSiO}_{4}$ cathodes has largely been attributed to this structural collapse. ${ }^{16-19}$ Both of these problems could be overcome with a mesoporous structure with internal pores to buffer the effect of the volume changes during lithium extraction and insertion, and a conductive surface carbon coating to enhance electronic conductivity.

Herein we report the use of an emulsion synthesis route to prepare a mesoporous cathode material from a mesoporous silica precursor. Emulsion synthesis has been used to prepare a range of lithium battery cathodes. ${ }^{20,21}$ In this work a water-in-oil emulsion synthesis route is used to prepare a lithium manganese silicate. Droplets of the aqueous phase consist of Li and Mn precursors and a solid mesoporous silica template in suspension. The aqueous phase is dispersed in an organic solvent containing a surfactant. The surfactant is distributed on 
the surface of the droplets of the aqueous phase (Fig. 1). During calcination in an inert atmosphere or vacuum, reaction occurs between the ordered mesoporous $\mathrm{SiO}_{2}$ and the $\mathrm{Li}$ and Mn salts in the aqueous solution to form a lithium manganese silicate. The mesoporous $\mathrm{SiO}_{2}$ acts as a template for the product and the mesoporosity and symmetry of the $\mathrm{SiO}_{2}$ precursor is retained in the product. The mesoporous architecture ensures that the electrolyte penetrates into the bulk of the material, as well as potentially accommodating the volume changes associated with lithium insertion and extraction during cell-cycling. The surfactant molecules on the surface of the droplets decompose to form a conductive surface coating to enhance electronic conductivity.

Stoichiometric amounts of lithium acetate dihydrate $\left(\mathrm{LiCH}_{3} \mathrm{COO} \cdot 2 \mathrm{H}_{2} \mathrm{O}\right)$ and manganese acetate tetrahydrate $\left(\mathrm{Mn}\left(\mathrm{CH}_{3} \mathrm{COO}\right)_{2} \cdot 4 \mathrm{H}_{2} \mathrm{O}\right)$ were dissolved in distilled water. A stoichiometric amount of either mesoporous silica SBA-15 $\left(\mathrm{SiO}_{2}\right)$, for the mesoporous sample, or fumed silica, for the bulk control sample, was added and suspended by sonication. This mixture formed the aqueous phase (Fig. 1). The oil phase consisted of cyclohexane as the primary component with 1-butanol and the surfactant Pluronic P123. The ratio of cyclohexane: 1butanol was typically $8.3: 1$ and $2 \mathrm{~g}$ of surfactant was added to $112 \mathrm{ml}$ of mixed organic solvents $(1.8 \mathrm{wt} \%)$. The solution was mixed vigorously for $1 / 2$ hour to dissolve the surfactant. The aqueous phase was then added to the oil phase to form a milky, water-in-oil emulsion which was magnetically stirred overnight at room temperature. The ratio of aqueous to non-aqueous phases was $1: 3.7$ by volume. The precipitate was then allowed to settle out, excess solvent was decanted off and the resulting product was dried on a hot-plate to give a pinky-brown gel. The gel was transferred to a crucible and heated at $500{ }^{\circ} \mathrm{C}$ for $10 \mathrm{~h}$ in dynamic vacuum to remove organic phases and then at $700{ }^{\circ} \mathrm{C}$ in vacuum in a closed tube furnace. The calcination of the precursor materials was performed in vacuum or under Ar, firstly, to prevent oxidation of the product phase and secondly, to retain the carbonaceous decomposition products from the surfactant to enhance the conductivity of the product. The temperature of $700{ }^{\circ} \mathrm{C}$ has been shown to be the optimal temperature to reduce impurities and form the $P m n 2_{1}$

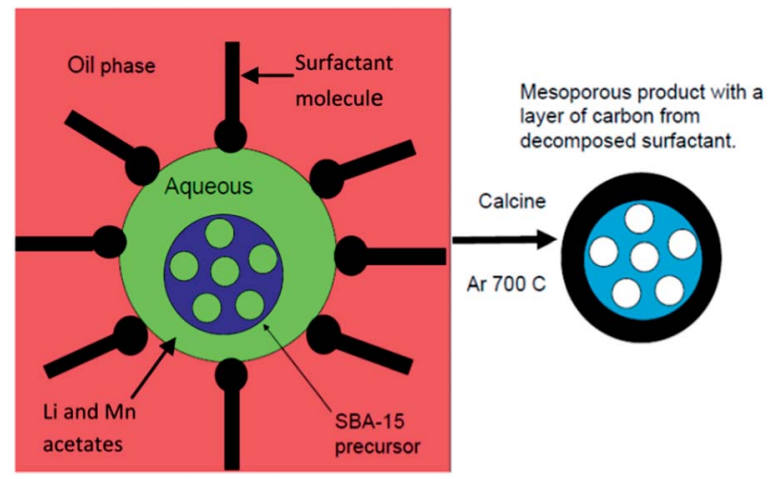

Fig. 1 A schematic diagram showing the formation of mesoporous manganese deficient lithium manganese silicate from SBA-15 using emulsion synthesis.

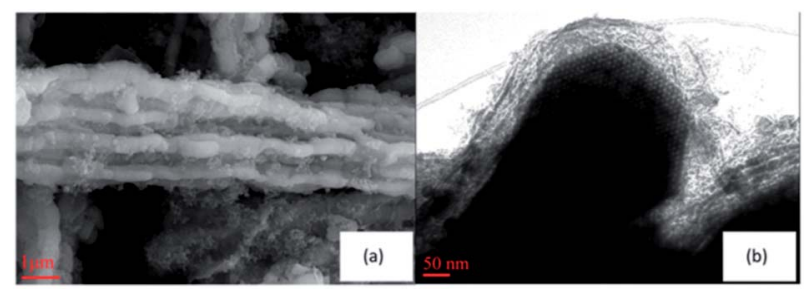

Fig. 2 Images of the mesoporous $\mathrm{Mn}$-deficient lithium manganese silicate prepared from an SBA-15 mesoporous $\mathrm{SiO}_{2}$ template (a) SEM image and (b) TEM image.

polymorph of $\mathrm{Li}_{2} \mathrm{MnSiO}_{4} \cdot{ }^{14}$ Emulsion synthesis using a stoichiometric mixture with a $\mathrm{Mn}: \mathrm{Si}$ ratio of $1: 1$, gave samples containing more than $15 \% \mathrm{MnO}$. Since $\mathrm{MnO}$ and other impurity phases like $\mathrm{Li}_{2} \mathrm{SiO}_{3}$ are electrochemically inactive, their content should be minimized. The Mn content in the starting mixture was therefore reduced to give a ratio of $\mathrm{Mn}: \mathrm{Si}$ of $0.7: 1$ for both the mesoporous and the bulk samples. As a result, the content of the electrochemically inactive MnO component decreased and a manganese deficient product was formed.

The morphology of the mesoporous product was characterized using scanning electron microscopy (SEM) and transmission electron microscopy (TEM) with a Zeiss Gemini UltraPlus and a JEOL 2100, respectively. The SEM images show that the morphology of the mesoporous SBA-15 precursor (Fig. S1†) is retained in the product (Fig. 2a) and that there is residual carbon from the synthesis on the surface of the product particles. The SEM image of the bulk product is given in Fig. S2. $\dagger$ The TEM image of the mesoporous product (Fig. 2b) shows that the hexagonal mesoporous structure of the SBA-15 precursor, confirmed by the small angle X-ray scattering data discussed later (Fig. 3), is retained in the product after calcination, with the hexagonal order clearly visible in the upper right hand corner of the image (Fig. 2b). A carbon coating, approximately $50 \mathrm{~nm}$ thick, from the decomposition of the surfactant under vacuum, is also clearly seen on the surface of the particles (Fig. 2b). Small angle X-ray scattering (SAXS) data were recorded with an Anton Parr 'SAXSess'from $q=0.2$ to $1.5 \mathrm{~nm}^{-1}$ (Fig. 3),

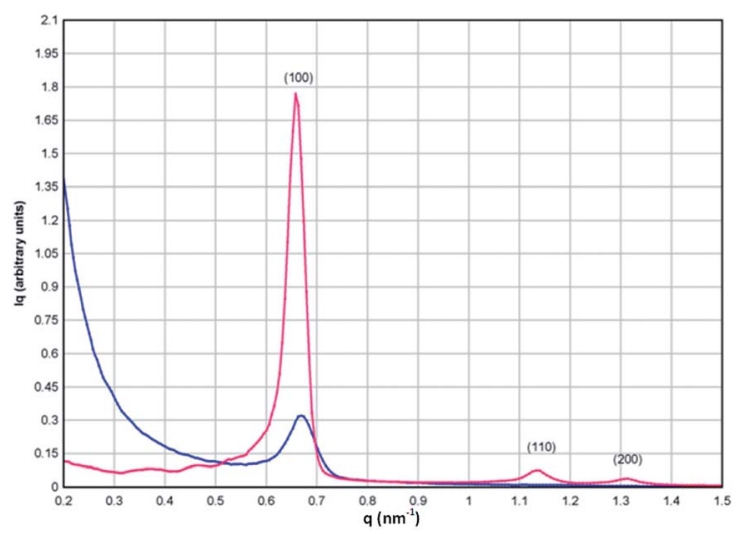

Fig. 3 SAXS data for the SBA-15 $\mathrm{SiO}_{2}$ precursor (red) and the mesoporous product (blue) showing retention of the mesoporous order of the precursor in the product phase. 
where $q$ is the momentum transfer vector defined as $q=$ $[4 \pi \sin (\theta) / \lambda]$, and $\theta$ is the scattering angle. The Bragg condition is fulfilled when $d=2 \pi / q$. The pattern of the SBA-15 precursor can be indexed to the hexagonal $P 6 \mathrm{~mm}$ space group with three well-defined peaks visible in the SAXS spectrum which can be indexed to the 100, 110 and 200 reflections with $d(100)=11.00$ $\mathrm{nm}$ for SBA-15 to give a lattice parameter, $a=12.7 \mathrm{~nm} .{ }^{22}$ The product phase also shows a well-defined 100 peak with $d(100)=$ $10.8 \mathrm{~nm}$, indicating that the product is mesoporous and retains the hexagonal symmetry of the $\mathrm{SiO}_{2}$ source. The higher order reflections are absent, and the intensity of the (100) peak is reduced, which indicates a reduction in the mesoporous order in the final product compared to the $\mathrm{SiO}_{2}$ precursor. The $a$ lattice parameter of the mesoporous product, calculated from the planar spacing in the TEM data (Fig. 2b), is $9.8 \mathrm{~nm}$, in good agreement with the value of $9.4 \mathrm{~nm}$ obtained from the SAXS data.

The phase composition and crystal structure of the product phases were analyzed with X-ray diffraction data obtained using a Siemens D5000 and $\mathrm{Cu} \mathrm{K} \alpha$ radiation (Fig. 4b and S3†). A simulated X-ray diffraction pattern for the $P m n 2_{1}$ polymorph of $\mathrm{Li}_{2} \mathrm{MnSiO}_{4}$ is given in Fig. 4a for comparison. ${ }^{11}$ Rietveld refinement of crystallographic models was performed with the GSAS program ${ }^{23}$ suite using the EXPGUI interface ${ }^{24}$ and the powder X-ray diffraction data of the mesoporous Mn-deficient product. The results show that it consists of a Mn-deficient $\mathrm{Li}_{2} \mathrm{Mn}_{0.87(3)} \mathrm{SiO}_{4}$ phase (88(5)\%) with impurities of $\mathrm{MnO}(4(1) \%)$ and $\mathrm{Li}_{2} \mathrm{SiO}_{3}(8(4) \%)$. Peaks of the mesoporous product are in good agreement with the stoichiometric phase in terms of peak position, although the peak intensities differ significantly due to the manganese deficiency. Lattice constants of the
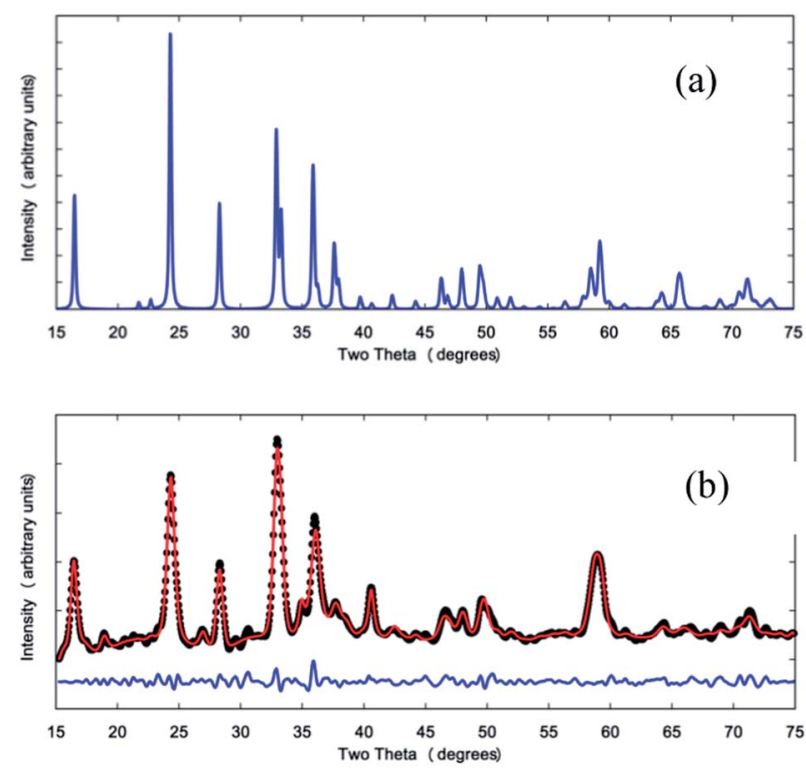

Fig. 4 (a) A simulated X-ray diffraction pattern of $\mathrm{Li}_{2} \mathrm{MnSiO}_{4}$ (b) Rietveld refinement results of structural models with the powder XRD pattern of the mesoporous $\mathrm{Mn}$-deficient product phase. Black dots represent the experimental data, the model is the red line through the data and the blue line below is the difference between the model and the data. mesoporous product are $a=6.307(2) \AA, b=5.389(2) \AA$ and $c=4.979(1) \AA$, slightly different to those of the standard $P m n 2_{1}$ polymorph of $\mathrm{Li}_{2} \mathrm{MnSiO}_{4}$ reported by Dominko et al. ${ }^{11}$ with $a=6.3109(9) \AA, b=5.3800(9) \AA$ and $c=4.9662(8) \AA$.

Research shows that it is very difficult to obtain phase-pure samples of $\mathrm{Li}_{2} \mathrm{MnSiO}_{4}$ and many samples, in reported studies, contain secondary impurity phases such as $\mathrm{MnO}$ and $\mathrm{Li}_{2} \mathrm{SiO}_{3},{ }^{19}$ even though they are electrochemically inactive and undesirable.

FTIR spectra of the mesoporous product were acquired using a Perkin-Elmer FTIR spectrometer with a diamond ATR in transmission mode. The spectra of the SBA-15 precursor and the mesoporous product are shown in Fig. S4. $\dagger$ The strong absorption band of the SBA- 15 at $\sim 1060 \mathrm{~cm}^{-1}$ is replaced in the product by strong bands in the $850-950 \mathrm{~cm}^{-1}$ range, typical of compounds containing $\mathrm{SiO}_{4}{ }^{4-}$ groups. ${ }^{25}$ This confirms the chemical conversion of the mesoporous $\mathrm{SiO}_{2}$ precursor into the product phase after calcination.

The electrochemical performance of the mesoporous electrodes was evaluated in Swagelok cells. The working electrode was formed from a slurry of active material: carbon black: PVDF in a ratio of $74: 13: 13$ in $N$-methylpyrrolidenone (NMP). The electrode slurry was coated onto $\mathrm{Al}$ current collectors and dried in vacuum at $80{ }^{\circ} \mathrm{C}$ for $12 \mathrm{~h}$. Cathodes were pressed at $15 \mathrm{MPa}$ prior to cell assembly. Typical cathode masses were 1-2 mg. Lithium metal foil was used as the counter electrode. The electrolyte was a solution of $1 \mathrm{M} \mathrm{LiPF}_{6}$ in $1: 1$ : ethylene carbonate: dimethyl carbonate (Merck Selectilyte). The electrochemical performance was determined using MTI cell cyclers at room temperature at a current rate of $20 \mathrm{~mA} \mathrm{~g}^{-1}$.

Fig. 5a shows the charge-discharge voltage profiles for cycles $1,2,5$ and 10 recorded in constant current mode between 1.8 and $4.8 \mathrm{~V}$ versus $\mathrm{Li}$. The initial discharge capacity, based on the mass of active material including residual carbon from the synthesis ( $\sim 5 \%$ determined by thermogravimetric analysis), was $170 \mathrm{~mA} \mathrm{~h} \mathrm{~g}{ }^{-1}$ with gradual capacity fade with cycling. After 11 cycles the cell was allowed to equilibrate and the cycling regime was changed to constant current-constant voltage cycling (Fig. 5b). The cell was charged to $4.8 \mathrm{~V}$ at $20 \mathrm{~mA} \mathrm{~g}^{-1}$, followed by a voltage hold at $4.8 \mathrm{~V}$ until the current dropped to $1 / 10^{\text {th }}$ of the initial current and then the cell was discharged at $20 \mathrm{~mA} \mathrm{~g}^{-1}$ to $1.8 \mathrm{~V}$. This change in charging regime resulted in a recovery of the lost capacity and improved capacity retention compared to the constant current cycling regime. The discharge capacity data of the cell containing the mesoporous cathode is shown in Fig. $5 \mathrm{c}$ and, for comparison, data for the bulk cathode, prepared under the same conditions, is included. Higher discharge capacity and better capacity retention with cycling was observed for the mesoporous Mn-deficient sample compared to the Mn-deficient bulk sample. TEM analysis of a cathode sample after 20 cycles shows lattice fringes consistent with the ordered, mesoporous structure (Fig. S5†), indicating that this structure is retained. On the other hand, Selected Area Electron Diffraction (SAED) of the cycled mesoporous material (Fig. S6†) shows a pattern consistent with an amorphous material, indicating that the lithium manganese silicate does not retain crystallinity with cycling despite the mesoporous structure. 

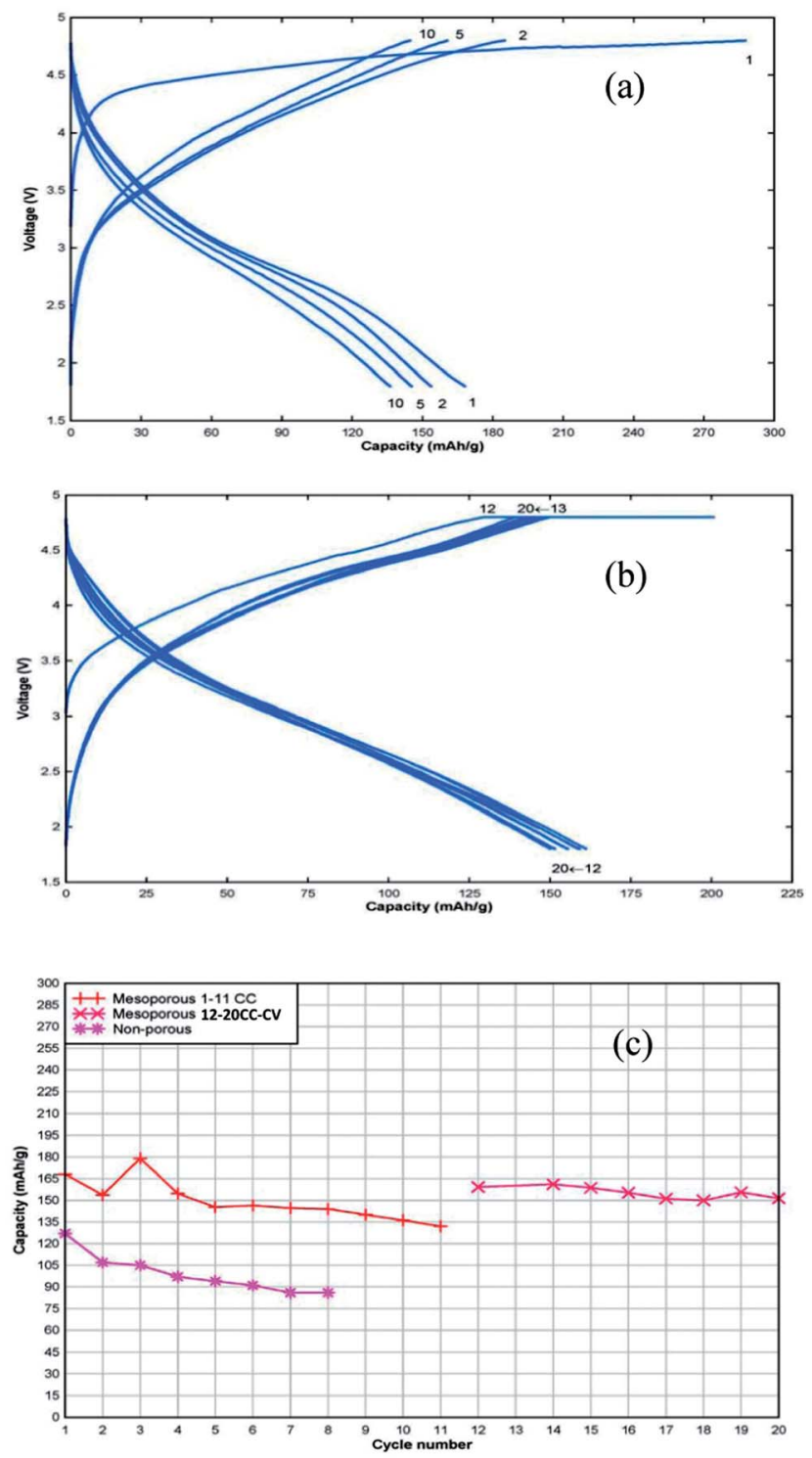

Fig. 5 Galvanostatic cycling curves of half-cells containing mesoporous cathodes (a) cycles 1-10 CC cycling (b) cycles 12-20 CC-CV cycling at room temperature and $20 \mathrm{~mA} \mathrm{~g}^{-1}$ (c) capacity vs. cycle number.

\section{Conclusions}

In this study we demonstrate that a mesoporous lithium manganese silicate can be synthesised from a mesoporous $\mathrm{SiO}_{2}$ precursor using an emulsion synthesis technique. A Mn-deficient product with composition $\mathrm{Li}_{2} \mathrm{Mn}_{0.87(3)} \mathrm{SiO}_{4}$ was produced that retains the mesoporous order of the silicate precursor. The mesoporous product gives a first discharge capacity of $170 \mathrm{~mA} \mathrm{~h}$ $\mathrm{g}^{-1}$ and good capacity retention using a constant currentconstant voltage charging regime at $20 \mathrm{~mA} \mathrm{~g}^{-1}$. The mesoporous nature of the product allows the electrolyte to penetrate into the bulk of the material to allow rapid lithium ion diffusion into the cathode. This effect results in much improved properties both in terms of capacity and capacity retention for the mesoporous material compared to bulk, non-porous material prepared in the same way. This improvement is observed in spite of amorphization of the lithium manganese silicate with cycling.

\section{Acknowledgements}

The authors would like to thank Prof. John Drennan and Dr Graeme Auchterlonie, Centre for Microscopy \& Microanalysis at the University of Queensland for the TEM data acquisition. We would also like to thank Dr Jennifer Whan of the Advanced Analytical Centre, James Cook University, for the XRD data collection. Thanks also to Dr Kevin Jack, of the Centre for Microscopy \& Microanalysis at the University of Queensland for the SAXS data collection. The authors are also grateful to Dr Tao Lu, Griffith University for the synthesis of the SBA-15 precursor used in this study. Thanks to Dr Mark Blackford and Dr Gregory Lumpkin of ANSTO for the TEM and SAED analysis of the cycled mesoporous cathode. We would also like to acknowledge AINSE support for this project on ALNGRA11120.

\section{Notes and references}

1 C. Daniel, JOM, 2008, 60, 43-48.

2 M. M. Thackeray, C. Wolverton and E. D. Isaacs, Energy Environ. Sci., 2012, 5, 7854-7863.

3 T. Xu, W. Wang, M. L. Gordin, D. H. Wang and D. W. Choi, JOM, 2010, 62, 24-30.

4 A. Manthiram, J. Phys. Chem. Lett., 2011, 2, 176-184.

5 Y. Wan and D. Zhao, Chem. Rev., 2007, 107, 2821-2860.

6 C. Liang, Z. Li and S. Dai, Angew. Chem., Int. Ed., 2008, 47, 3696-3717.

7 C. Jiang, E. Hosono and H. Zhou, Nano Today, 2006, 1, 28-33.

8 Y. Ye, C. Jo, I. Jeong and J. Lee, Nanoscale, 2013, 5, 45844605.

9 F. Jiao and P. G. Bruce, Adv. Mater., 2007, 19, 657-660.

10 Y. G. Wang, H. Q. Li, P. He, E. Hosono and H. S. Zhou, Nanoscale, 2010, 2, 1294-1305.

11 R. Dominko, M. Bele, M. Gaberscek, A. Meden, M. Remskar and J. Jamnik, Electrochem. Commun., 2006, 8, 217-222.

12 R. Dominko, M. Bele, A. Kokalj, M. Gaberscek and J. Jamnik, J. Power Sources, 2007, 174, 457-461.

13 A. Kokalj, R. Dominko, G. Mali, A. Meden, M. Gaberscek and J. Jamnik, Chem. Mater., 2007, 19, 3633-3640.

14 I. Belharouak, A. Abouimrane and K. Amine, J. Phys. Chem. C, 2009, 113, 20733-20737.

15 Y. X. Li, Z. L. Gong and Y. Yang, J. Power Sources, 2007, 174, 528-532.

16 C. Deng, S. Zhang, B. L. Fu, S. Y. Yang and L. Ma, Mater. Chem. Phys., 2010, 120, 14-17.

17 R. Dominko, J. Power Sources, 2008, 184, 462-468.

18 A. Manthiram, T. Muraliganth and K. R. Stroukoff, Chem. Mater., 2010, 22, 5754-5761.

19 R. J. Gummow and Y. He, J. Power Sources, 2014, 253, 315331.

20 M. Seung-Taek, K. Shinichi, K. Naoaki and C. Hoon-Taek, ChemInform, 2002, 33, 223. 
21 T. Dong-Ge, L. Qiong-Yu, W. Ni-Ni, T. Ai-Dong, T. Lian-Xing, H. Ke-Long and J. Xiao-Yang, Mater. Chem. Phys., 2005, 94, 423-428.

22 D. Y. Zhao, Q. S. Huo, J. L. Feng, B. F. Chmelka and G. D. Stucky, J. Am. Chem. Soc., 1998, 120, 6024-6036.
23 A. C. Larson and R. B. Von Dreele, Los Alamos National Laboratory Report LAUR, 1994, pp. 86-748.

24 B. H. Toby, J. Appl. Crystallogr., 2001, 34, 210-213.

25 K. Zaghib, A. A. Salah, N. Ravet, A. Mauger, F. Gendron and C. M. Julien, J. Power Sources, 2006, 160, 1381-1386. 